\title{
Review Article \\ Effects of Probiotics, Prebiotics, and Synbiotics on Hypercholesterolemia: A Review
}

\author{
Marimuthu Anandharaj, Balayogan Sivasankari, and Rizwana Parveen Rani \\ Department of Biology, Gandhigram Rural Institute-Deemed University, Gandhigram, Dindigul, Tamilnadu, India \\ Correspondence should be addressed to Marimuthu Anandharaj; anandharaj49@gmail.com
}

Received 13 December 2013; Accepted 18 January 2014; Published 27 February 2014

Academic Editors: A. Castañeyra-Perdomo, N. Heng, and S.-L. Pan

Copyright (C) 2014 Marimuthu Anandharaj et al. This is an open access article distributed under the Creative Commons Attribution License, which permits unrestricted use, distribution, and reproduction in any medium, provided the original work is properly cited.

\begin{abstract}
Cholesterol plays a major role in human health. High cholesterol is a leading risk factor for human cardiovascular disease such as atherosclerosis, coronary heart disease, and stroke. Excess cholesterol in the bloodstream can form plaque in the artery walls. Hypercholesterolemia is a major risk factor for the development of atherosclerosis. A number of pharmacological and nonpharmacological (including dietary) approaches being employed to reduce the cholesterol level. Numerous drugs that lower serum cholesterol have been developed to treat hypercholesterolemic patients, the best example being the statins drugs (Atorvastatin, Simvastatin, Rosuvastatin, and Lovastatin). However, the undesirable side effects of these compounds were observed and have caused concern about their long term therapeutic use. Several studies have been reported that the consumption of fermented dairy products decreases serum cholesterol. Probiotics are live microorganisms that promote health benefits upon consumption, while prebiotics are nondigestible food ingredients that selectively stimulate the growth of beneficial microorganisms in the gastrointestinal tract. Probiotics and prebiotics have been suggested to reduce cholesterol via various mechanisms without any deleterious effect to the human health. This paper may throw some light to prove the ability of these synbiotics as a novel alternative or adjuvant to chemical drugs to help fight the hypercholesterolemic problem.
\end{abstract}

\section{Introduction}

Elevated serum cholesterol level is widely recognized as a contributory risk factor for the development of cardiovascular diseases (CVD) such as atherosclerosis, coronary heart diseases, and hypertension. The World Health Organization (WHO) has predicted that by 2030 , CVD will remain the leading cause of death and will affect approximately 23.6 million people globally [1]. It has been reported that even a $1 \%$ reduction in serum cholesterol could reduce the risk of coronary heart disease by 2-3\% [2]. Hypercholesterolemia contributed to $45 \%$ of heart attacks in Western Europe and $35 \%$ of heart attacks in Central and Eastern Europe from 1999 to $2003[3,4]$. The risk of heart attack is three times higher in those with hypercholesterolemia, compared to those who have normal blood lipid profiles. The WHO delineated that unhealthy diets such as those high in fat, salt, and free sugar and low in complex carbohydrates lead to an increased risk of cardiovascular diseases [5].
1.1. Good and Bad Cholesterol. Cholesterol is a waxy, fat-like substance found in the body cells of humans and animals. Sometimes cholesterol is referred to as "good" cholesterol and "bad" cholesterol. Actually these descriptions refer to the substances called lipoproteins that carry cholesterol throughout the body in the bloodstream. Lipoproteins are a combination of varying amounts of fats and proteins.

"Good" cholesterol is associated with high density lipoproteins (HDLs). HDLs are believed to remove excess cholesterol from the body; therefore higher levels of HDLs are also believed to be associated with lower rates of heart disease. "Bad" cholesterol is associated with low density lipoproteins (LDLs). LDLs carry cholesterol in the blood to body cells. High levels of LDLs are usually associated with elevated blood cholesterol and an increased risk of heart disease due to cholesterol and fat being deposited in the arteries. These fatty deposits decrease the interior size of the arteries so the blood supply is reduced, thus increasing the risk of heart disease and stroke. 
Nowadays numerous drugs that lower serum cholesterol have been developed to treat hypercholesterolemic patients. However, the undesirable side effects of these compounds were observed and have caused concerns about their long term therapeutic use. For this reason, a number of nonpharmacological approaches (including dietary ones) resulting in serum cholesterol reduction were tested. Various approaches have been used to alleviate this issue, including the use of probiotics and/or prebiotics.

\section{Probiotics}

The word "probiotic" comes from the Greek word "pro bios" which means "for life" as opposed to "antibiotics" which means "against life." The history of probiotics began with the consumption of fermented foods by Greek and Romans $[6,7]$. In 1908, Russian researcher Elie Metchnikoff, who got a Nobel Prize, firstly proposed the beneficial effects of probiotic microorganisms on human health. Metchnikoff hypothesized that Bulgarians are healthy and long-lived people because of the consumption of fermented milk products which consist of rod-shaped bacteria (Lactobacillus spp.). Therefore, these bacteria affect the gut microflora positively and decrease the microbial toxic activity in human intestine $[6,8,9]$.

The term "probiotic" was first used by Lilly and Stillwell in 1965 to describe substances which kindle the growth of other microorganisms. After this year, the word "probiotic" was used in different interpretations based on its mechanism and its effects on human health. This definition was improved by Parker in 1974 [10]. Parker defined "probiotic" as "substances and organisms which contribute to intestinal microbial balance." In 1989, definition for probiotics was improved by Fuller [11]. Probiotic microorganisms do not act exclusively in the large intestine via affecting the intestinal flora. They also affect other organs, either by modulating immunological parameters, intestinal permeability, and bacterial translocation or by providing bioactive or otherwise regulatory metabolites. Therefore, broader definitions have been suggested, that is, by Schrezenmeir and de Vrese [12], by the International Life Sciences Institute (ILSI) Europe, according to which probiotics have been defined as "a viable microbial food supplement which beneficially influences the health of the host" [13]. More than 400 bacterial species exist in the human intestinal tract. It is an enormously complex ecosystem that includes both anaerobic and facultative anaerobic microorganisms [14]. The composition of the gut microflora is constant but can be affected by some factors such as age, diet, environment, stress, and medication. The majority of probiotic microorganisms belong to the genera Lactobacillus and Bifidobacterium. Besides this, several other bacteria and some yeasts also have probiotic properties (Table 1). Lactobacilli and Bifidobacteria are Gram positive lactic acid-producing bacteria that constitute a major part of the normal intestinal microflora in animals and humans [15].

Lactobacilli are nonspore forming rod-shaped bacteria. They have complex nutritional requirements and are strictly fermentative, aerotolerant or anaerobic, and aciduric or
TABLE 1: The probiotic microorganisms which are used to feed both man and animals.

\begin{tabular}{|c|c|c|}
\hline $\begin{array}{l}\text { Lactobacillus } \\
\text { species }\end{array}$ & $\begin{array}{c}\text { Bifidobacterium } \\
\text { species }\end{array}$ & Others \\
\hline $\begin{array}{l}\text { L. acidophilus } \\
\text { L. rhamnosus } \\
\text { L. gasseri } \\
\text { L. casei } \\
\text { L. reuteri } \\
\text { L. delbrueckii } \\
\text { subsp. bulgaricus } \\
\text { L. crispatus } \\
\text { L. plantarum } \\
\text { L. salivarius } \\
\text { L. johnsonii } \\
\text { L. gallinarum } \\
\text { L. plantarum } \\
\text { L. fermentum } \\
\text { L. helveticus } \\
\text { L. oris }\end{array}$ & $\begin{array}{l}\text { B. bifidum } \\
\text { B. animalis } \\
\text { B. breve } \\
\text { B. infantis } \\
\text { B. longum } \\
\text { B. lactis } \\
\text { B. adolescentis }\end{array}$ & $\begin{array}{c}\text { Enterococcus faecalis } \\
\text { Enterococcus faecium } \\
\text { Streptococcus salivarius } \\
\text { subsp. } \\
\text { thermophilus } \\
\text { Lactococcus lactis subsp. } \\
\text { lactis } \\
\text { Lactococcus lactis subsp. } \\
\text { cremoris } \\
\text { Propionibacterium } \\
\text { freudenreichii } \\
\text { Pediococcus acidilactici } \\
\text { Saccharomyces boulardii } \\
\text { Leuconostoc } \\
\text { mesenteroides } \\
\text { Weissella cibaria } \\
\text { Weissella confusa }\end{array}$ \\
\hline
\end{tabular}

acidophilic. Lactobacilli are found in a variety of habitats where rich, carbohydrate-containing substrates are available, such as on human and animal mucosal membranes, on plants or material of plant origin, on sewage, and on fermented milk products, fermenting or spoiling food [15].

Bifidobacteria comprise a major part of the normal intestinal microflora in humans throughout life. The number of Bifidobacteria in the colon of adults is $10^{10}-10^{11} \mathrm{cfu} / \mathrm{gram}$, but this number decreases with age. Most of the Bifidobacterial species are strictly anaerobic, nonmotile, and nonsporulating rods with a varying morphological appearance [15].

2.1. Sources of Probiotics. The most common sources of probiotics are yogurt, cultured buttermilk, and cheese. Cultured buttermilk is made with bacteria that produce lactic acid, which makes the product sour. Some cultured cheese use bacteria to finish the maturation of the cheese. Another fermented dairy product is Kefir. Traditionally, yogurt has only one or two bacteria whereas Kefir tends to have several probiotic bacteria. Other foods that are produced by bacterial fermentation are Japanese miso, tempeh, sauerkraut, beer, sour dough, bread, chocolate, kimchi, olives, and pickles [16]. The dominant food vehicles for probiotics are still yogurts and fermented milks, both of which provide a relatively low $\mathrm{pH}$ environment in which the probiotic bacteria must survive [17]. However, many studies show that probiotics strains are also found in nondairy fermented substrates [12]. Some of the nondairy probiotic products are cereal, legume, cabbage, maize, pearl millet, vegetable, sorghum, and so forth [18].

2.2. Health Benefits of Probiotics. Probiotics may play a beneficial role in several medical conditions, including diarrhea, gastroenteritis, irritable bowel syndrome, inflammatory bowel disease, cancer, depressed immune function, infant 


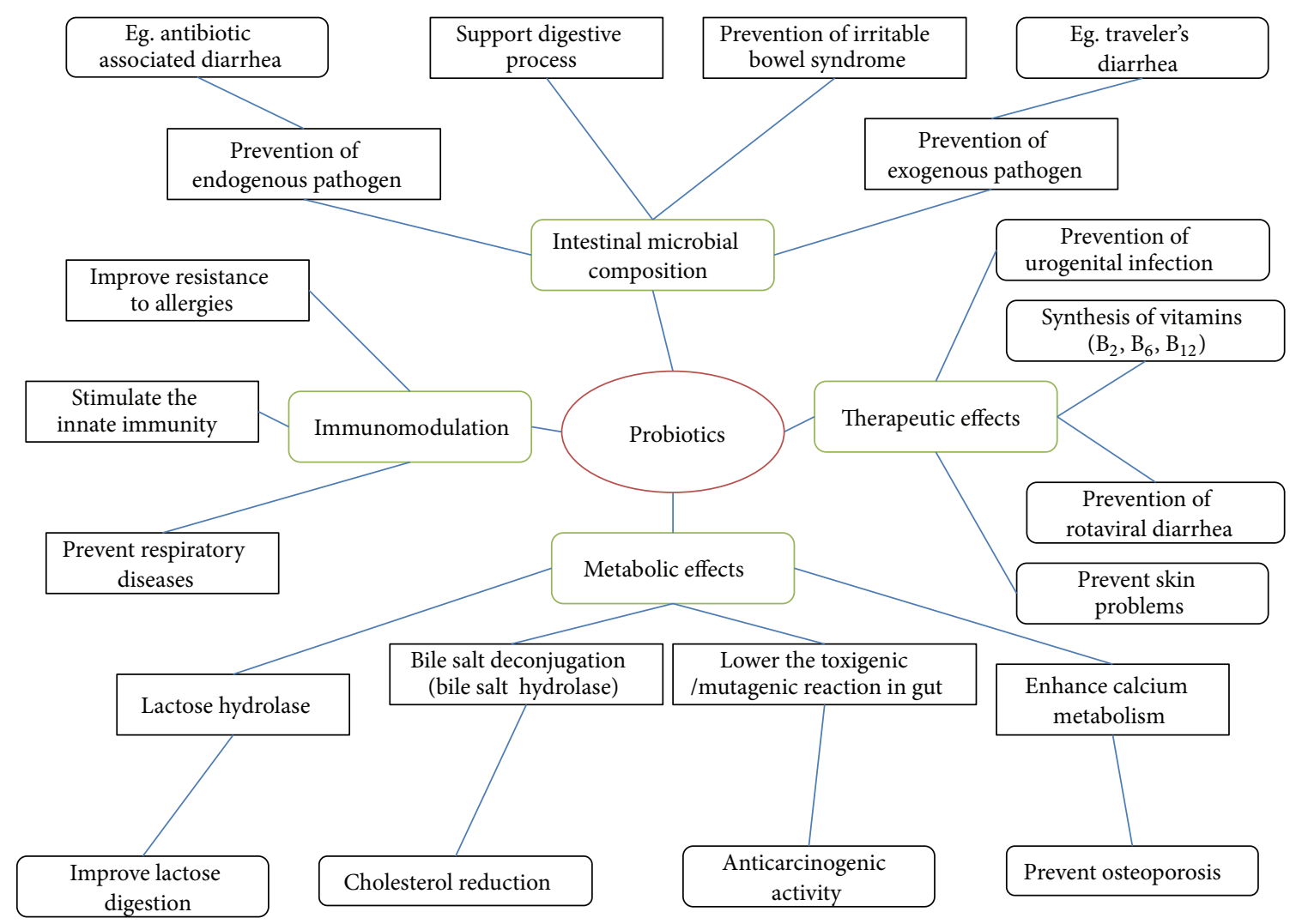

FIgURE 1: Overall health benefits of probiotic bacteria on human health.

allergies, failure-to-thrive, hyperlipidemia, hepatic diseases, Helicobacter pylori infections, and others, all of which were suggested by certain research studies to improve with the use of probiotics [19]. The overall health benefits of probiotic microorganisms are represented in Figure 1.

Mechanisms of action of probiotics that have been suggested include receptor competition, effects on mucin secretion and immunomodulation of gut associated lymphoid tissue, increased immunosuppressive and decreased proinflammatory mediators [20]. Probiotic microbes exert beneficial effect via a wide array of actions. These include resistance to colonization, production of antimicrobial substances, inhibition of pathogen adhesion, degradation of toxins, stimulation of local and peripheral immunity, stimulation of brush border enzyme activity, stimulation of secretory$\operatorname{IgA}$, and prevention of microbial translocation. Because of these varied actions, unlikely pathogens will develop resistance against probiotic agents. Colonization resistance is the ability of the normal flora to protect itself against unnecessary colonization of enteric pathogens in the GI tract. Colonization resistance is achieved by complex interactions between the different resident bacteria of the mucosal microflora [21]. The inhibitory chemical substance, bacteriocin, is defined as protein antibiotics of the type of colicin, that is, a substance characterized by its lethal biosynthesis, its killing activity of predominant intraspecies, and its adsorption to specific receptors on the surface of bacteriocin-sensitive cells [22].

\section{Prebiotics}

The term prebiotic was first used by Gibson and Roberfroid in 1995 [23]. Prebiotics are "indigestible fermented food substrates that selectively stimulate the growth, composition, and activity of microflora in gastrointestinal tract and thus improve hosts' health and well-being" [24]. Lactulose was used 50 years ago as a prebiotic formula supplement to increase the number of Lactobacillus strains in infants' intestines [25].

Fructooligosaccharides, inulin, oligofructose, lactulose, and galactooligosaccharides have been identified as prebiotics due to characteristics such as resistance to gastric acidity and hydrolysis by mammalian enzymes and they are fermented by gastrointestinal microflora to further selectively stimulate the growth and activity of beneficial microorganisms. The number of new compounds which have gut resistant properties and selective fermentability by intestinal microorganisms are identified and developed as prebiotics $[26,27]$. These include oligosaccharides (isomaltooligosaccharides, lactosucrose, xylooligosaccharides, and glucooligosaccharides), sugar alcohols, and polysaccharides (starch, resistant starch, and modified starch) [28].

Fermentation of oligofructose in the colon is due to the presence of intestinal microflora, which confers beneficial effects to humans, which include increasing the numbers of probiotics in the colon, increasing calcium absorption, 
increasing fecal weight, shortening gastrointestinal transit time, and possibly, lowering blood lipid levels.

3.1. Sources of Prebiotics. Traditional dietary sources of prebiotics include soybeans, inulin sources (such as Jerusalem artichoke, jicama, and chicory root), raw oats, unrefined wheat, unrefined barley, and yacon. Some of the oligosaccharides that naturally occur in breast milk are believed to play an important role in the development of a healthy immune system in infants. The breast feeding infants have flora dominated by Lactobacilli and Bifidobacteria, which are part of the baby's defence against pathogens, which is an important primer for the immune system $[29,30]$. These floras are nurtured by the oligosaccharides of breast milk, which is considered to be the original prebiotic. While some peptides, proteins, and certain lipids are potential prebiotics, nondigestible carbohydrates, in particular nondigestible oligosaccharides, have received the most attention [31].

\section{Synbiotics}

When probiotics and prebiotics are used in combination, they are known as "synbiotics." The combination of suitable probiotics and prebiotics enhances survival and activity of the organism, for example, an FOS in conjunction with a Bifidobacterium strain or lactitol in conjunction with Lactobacillus strains [23]. The combination of prebiotic and probiotic has synergistic effects because in addition to promoting growth of existing strains of beneficial bacteria in the colon, synbiotics also act to improve the survival, implantation, and growth of newly added probiotic strains.

\section{Mechanism of Cholesterol Reduction}

A number of cholesterol lowering mechanisms by Lactobacillus strains have been proposed. The hypocholesterolemic effect of the probiotics has also been attributed to their ability to bind cholesterol in the small intestines. One of the most important mechanisms is through the bile salt hydrolase (BSH) enzyme, the enzyme responsible for bile salt deconjugation in the enterohepatic circulation. The BSH activity was able to hydrolyze conjugated glycodeoxycholic acid and taurodeoxycholic acid, leading to the deconjugation of glycoand tauro-bile acids. It has been detected in several lactic acid bacteria (LAB) species indigenous to the gastrointestinal tract [32-35]. Many researchers suggested that $\mathrm{BSH}$ activity should be a requirement in the selection of probiotic organisms with cholesterol-lowering properties, as nondeconjugating organisms do not appear to be able to remove cholesterol from the culture medium to any significant extent [36]. In recent years, the possibility of using bile salt deconjugation by lactic acid bacteria to treat hypercholesterolemia in humans has received increased attention [37, 38]. The major source of cholesterol in the human body includes biosynthesis by the liver and absorption by the intestines. These two factors are determining the overall cholesterol level. Recent research has found that several pathways may be involved

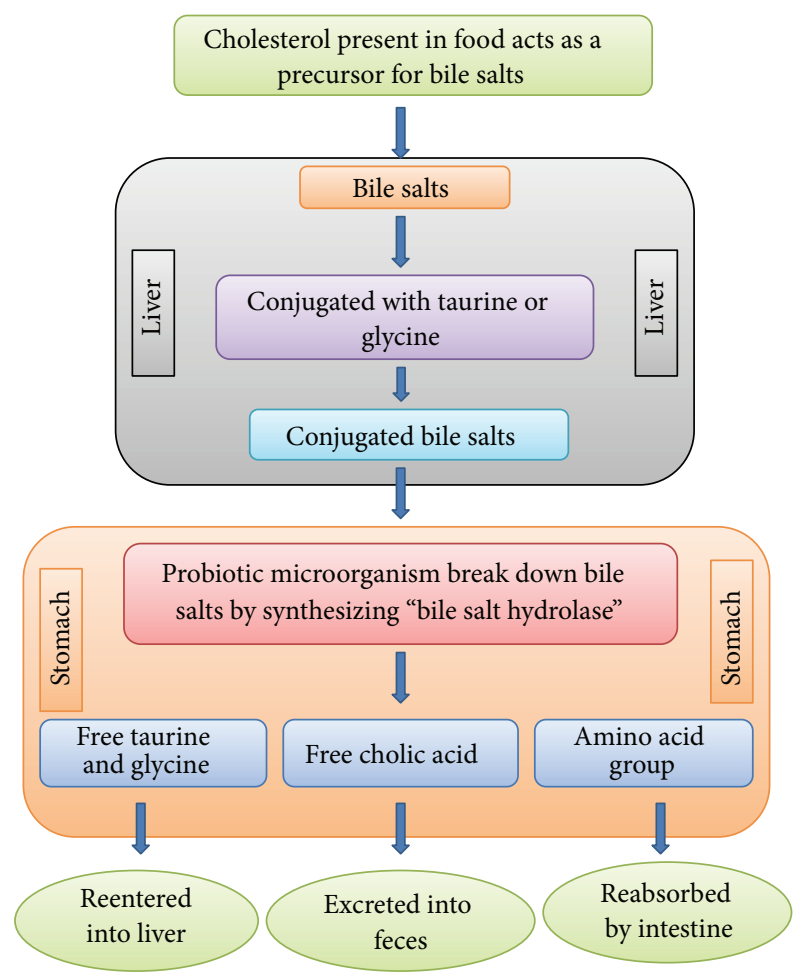

FIGURE 2: Cholesterol reduction mechanism of probiotic microorganisms.

in the mechanism, which governs the cholesterol-lowering effects of probiotics both in vitro and in vivo, but these mechanisms are still not clearly understood. The overall cholesterol reduction mechanism of probiotic microorganisms are represented in Figure 2.

5.1. Effects of Probiotics on Cholesterol Reduction. The first scientific report associating lactic acid bacteria with a reduction in serum cholesterol was published in 1974 by Mann and Spoerry [39]; they observed an $18 \%$ reduction in the total serum cholesterol level of warriors of an African tribe (Masai and Sambura) whose regular diet included milk fermented by Lactobacillus. Anderson and Gilliland reported that Lactobacillus acidophilus reduces blood cholesterol by a direct breakdown of cholesterol and deconjugation of bile salt. They also examined the effects of consumption of yogurt reduce the serum cholesterol level significantly [40].

Anderson and Gilliland reported the effect of fermented milk containing L. acidophilus L1 on serum cholesterol in hypercholesterolemic subjects. This randomized, doubleblind, placebo-controlled, and crossover 10-week study was designed for forty-eight volunteers with a serum cholesterol level ranging from $5.40 \mathrm{mmol} / \mathrm{L}$ to $8.32 \mathrm{mmol} / \mathrm{L}$. A daily consumption of $200 \mathrm{~g}$ of yogurt containing L. acidophilus L1 after dinner contributed to a significant $(P<0.05)$ reduction in serum cholesterol concentration $(-2.4 \%)$ compared to the placebo group [40]. Liong and Shah screened eleven strains of lactobacilli and analyzed bile salt deconjugation ability, bile salt hydrolase activity (BSH), and coprecipitation of 
cholesterol with deconjugated bile. Lactobacillus acidophilus strains had a higher deconjugation ability than L. casei strains. Cholesterol coprecipitation with deconjugated bile increased with decreasing $\mathrm{pH}$ [41].

In another study Xiao et al. evaluated the effects of a low-fat yogurt containing $10^{8} \mathrm{CFU} / \mathrm{g}$ of B. longum BL1 on lipid profiles of thirty-two volunteers. Results from this study showed a significant $(P<0.05)$ decrease in serum total cholesterol, LDL-cholesterol, and triglycerides after 4-weeks and a $14.5 \%$ increase in HDL-cholesterol when compared with the control (yogurt without B. longum BL1; $P<0.05$ ) [42].

The probiotic microorganisms isolated from fermented milk reduce the cholesterol in the presence of $0.3 \%$ bile salt ranging from $28 \%$ to $83 \%$. And some strains were able to reduce cholesterol to more than $70 \%$ [43]. The study performed by Kim and coworkers (2008) characterized the factors which are responsible for the cholesterol reduction by Lactobacillus acidophilus ATCC 43121. The results showed that the cell-free supernatant (CFS) produced by ATCC 43121 in the presence of bile salts could also reduce the cholesterol in the broth, unlike previous reports which suggested a mechanism by live cells only [44].

A study on the reduction of cholesterol showed that Lactobacillus reuteri CRL 1098 decreased total cholesterol by $38 \%$ when it is given to mice for 7 days in the rate of $10^{4}$ cells/day. This dose of Lactobacillus reuteri caused a $40 \%$ reduction in triglycerides and a $20 \%$ increase in the ratio of high density lipoprotein to low density lipoprotein without bacterial translocation of the native microflora into the spleen and liver [45].

5.2. Effects of Prebiotics on Cholesterol Reduction. Prebiotics are an alternative for probiotics or their cofactors. They are defined as nondigestible or low-digestible food ingredients that benefit the host organism by selectively stimulating the growth or activity of one or a limited number of probiotic bacteria in the colon $[31,46,47]$. Brighenti et al. used twelve healthy persons (male) for a 12-week trial; the researchers found that the daily consumption of $50 \mathrm{~g}$ of a rice-based ready-to-eat cereal containing $18 \%$ inulin significantly $(P<$ $0.05)$ reduced plasma total cholesterol and triacylglycerols by $7.9 \%( \pm 5.4)$ and $21.2 \%( \pm 7.8)$, respectively, compared to control [48].

Fernandez et al. administered $10 \mathrm{~g} / 100 \mathrm{~g}$ of resistant starch (obtained from the Meer Corporation) to male Hartley guinea pigs (body weight of 300-400 g) for four weeks using sixteen male guinea pigs and the results showed that the resistant starch significantly reduced $(P<0.01)$ plasma cholesterol by $27.4 \%$ and LDL-cholesterol concentration by $28.0 \%$ compared to the control group [49].

Causey et al. performed a randomized, double-blind, and crossover study using hypercholesterolemic subjects to evaluate the effects of inulin extracted from chicory root on blood cholesterol levels of subjects. This study involved twelve men; they were randomly assigned to two groups, namely the control group (consumed one pint of vanilla ice-cream without inulin) and the inulin group (consumed one pint of vanilla ice-cream containing $20 \mathrm{~g}$ of inulin). The 3 -week study found that the daily intake of $20 \mathrm{~g}$ of inulin significantly $(P<0.05)$ reduced serum triglycerides [50].

Mortensen et al. found that forty male mice fed with a purified diet with $10 \%$ of long-chained fructan for 16 weeks showed that the fructan significantly reduced blood cholesterol by $29.7 \%(P<0.001)$, LDL-cholesterol concentration by 25.9\% $(P<0.01)$, IDL-cholesterol level by 39.4\% $(P<0.001)$, and VLDL-cholesterol concentration by $37.3 \%(P<0.05)$ compared to the control group [51].

Favier et al. evaluated the hypocholesterolemic effects of $\beta$-cyclodextrin in a randomized, placebo-controlled, and parallel design trial involving ten male Wistar rats (mean body weight of $150 \mathrm{~g}$ ). In this 21-day trial, the authors found that daily consumption of $25 \mathrm{~g} / \mathrm{kg}$ of $\beta$-cyclodextrin significantly $(P<0.05)$ reduced plasma cholesterol and triacylglycerols by $25.9 \%$ and $35.0 \%$, respectively, compared to the control group [52].

5.3. Effects of Synbiotics on Cholesterol Reduction. Liong and Shah evaluated the effectiveness of 3 synbiotic diets [(a) containing Lactobacillus casei ASCC 292 and fructooligosaccharides (LF diet), (b) containing L. casei ASCC 292 and maltodextrin (LM diet), and (c) containing L. casei ASCC 292, fructooligosaccharide, and maltodextrin (LFM diet)] to reduce serum cholesterol in male Winstar rats. Results from this study showed that the synbiotic diet that contained L. casei ASCC 292, fructooligosaccharide, and maltodextrin beneficially altered cholesterol levels and produced a healthier bowel microbial population without translocation of lactobacilli to other organs [53].

Schaafsma et al. conducted a study involving thirty volunteers (aged 33-64 years old, body weight $66.5-98.0 \mathrm{~kg}$ ) with mean total cholesterol of $5.23 \pm 1.03 \mathrm{mmol} / \mathrm{L}$ and LDL-cholesterol of $3.42 \pm 0.94 \mathrm{mmol} / \mathrm{L}$. In this study, the authors observed that daily consumption of $375 \mathrm{~mL}$ synbiotic milk [containing 107-108 CFU/g of Lactobacillus acidophilus and $2.5 \%(\mathrm{~g} / 100 \mathrm{~g})$ of fructooligosaccharides] resulted in a significant decline in total cholesterol $(P<0.001)$, LDLcholesterol $(P<0.005)$, and LDL/HDL ratio $(P<0.05)$ of $4.4 \%, 5.4 \%$, and $5.3 \%$, respectively [54].

\section{Conclusion and Future Prospects}

Probiotics, prebiotics, and their combinations have been found to be clinically effective for a large number of disorders which include hypercholesterolemia. The use of any probiotic and prebiotic substances for the enrichment of fermented products provides its delivery into the human gastrointestinal tract and hence, a stimulation of beneficial health effects. A number of cholesterol removal mechanisms by probiotics have been proposed, which include assimilation of cholesterol by growing cells, binding of cholesterol to cellular surface, incorporation of cholesterol into the cellular membrane, deconjugation of bile via bile salt hydrolase, and coprecipitation of cholesterol with deconjugated bile. But the exact mechanisms remain unclear and controversial. Much work has already been accomplished to help us to understand 
probiotics and the manner in which they function. However, some issues like dosage and viability of probiotic strains, industrial standardization, and safety aspects are needed to be studied well. In recent times, cholesterol reduction, cancer prevention, and immunology are the three major areas of research on probiotics and prebiotics. Genetic engineering and other approaches are being used to enhance the beneficial effects of probiotic microbes. Supplementation of promising strains of probiotic organisms may offer exciting solutions for reducing the problem of high cholesterol levels in human beings. However, extensive research is required to screen the potent probiotic strains and their evaluation for the effective management of good and bad cholesterol in the body and the sustainability of the desired results. The combination of probiotics and prebiotics significantly reduces the serum cholesterol level and that can be used as an alternative remedy for hypercholesterolemic problems without any side effects to the consumers.

\section{Conflict of Interests}

The authors declare that there is no conflict of interests regarding the publication of this paper.

\section{Acknowledgment}

The authors are thankful to the Department of Biology, Gandhigram Rural Institute-Deemed University, Gandhigram, Tamilnadu, India.

\section{References}

[1] WHO, "Cardiovascular Disease," Fact sheet 317, WHO, Geneva, Switzerland, 2009, http://www.who.int/mediacentre/ factsheets/fs317/en/print.html.

[2] J. E. Manson, H. Tosteson, P. M. Ridker et al., "Medical progress: the primary prevention of myocardial infarction," New England Journal of Medicine, vol. 326, no. 21, pp. 1406-1416, 1992.

[3] P. S. Yusuf, S. Hawken, S. Ônpuu et al., "Effect of potentially modifiable risk factors associated with myocardial infarction in 52 countries (the INTERHEART study): case-control study," The Lancet, vol. 364, no. 9438, pp. 937-952, 2004.

[4] M. Kumar, R. Nagpal, R. Kumar et al., "Cholesterol-lowering probiotics as potential biotherapeutics for metabolic diseases," Experimental Diabetes Research, vol. 2012, Article ID 902917, 14 pages, 2012.

[5] WHO, "Diet, Nutrition and Prevention of Chronic Diseases," Report of a Joint WHO/FAO Expert Consultation, Geneva, Switzerland, 2003.

[6] M. R. Gismondo, L. Drago, and A. Lombardi, "Review of probiotics available to modify gastrointestinal flora," International Journal of Antimicrobial Agents, vol. 12, no. 4, pp. 287-292, 1999.

[7] F. Guarner, G. Perdigon, G. Corthier, S. Salminen, B. Koletzko, and L. Morelli, "Should yoghurt cultures be considered probiotic?" British Journal of Nutrition, vol. 93, no. 6, pp. 783-786, 2005.

[8] İ. Çakır, Determination of some probiotic properties on Lactobacilli and Bifidobacteria [Ph.D. thesis], Ankara University, 2003.
[9] E. L. Chuayana Jr., C. V. Ponce, M. R. B. Rivera, and E. C. Cabrera, "Antimicrobial activity of probiotics from milk products," The Philippine Journal of Microbiology and Infectious Diseases, vol. 32, no. 2, pp. 71-74, 2003.

[10] R. B. Parker, "Probiotics: the other half of the antibiotic story," Animal Nutrition and Health, vol. 29, pp. 4-8, 1974.

[11] R. Fuller, "Probiotics in man and animals," Journal of Applied Bacteriology, vol. 66, no. 5, pp. 365-378, 1989.

[12] J. Schrezenmeir and M. De Vrese, "Probiotics, prebiotics, and synbiotics-approaching a definition," American Journal of Clinical Nutrition, vol. 73, no. 2, pp. 361-364, 2001.

[13] S. Salminen, C. Bouley, M.-C. Boutron-Ruault et al., "Functional food science and gastrointestinal physiology and function," British Journal of Nutrition, vol. 80, no. 1, pp. S147-S171, 1998.

[14] A. S. Naidu, W. R. Bidlack, and R. A. Clemens, "Probiotic spectra of lactic acid bacteria (LAB)," Critical Reviews in Food Science and Nutrition, vol. 39, no. 1, pp. 13-126, 1999.

[15] M. de Vrese and J. Schrezenmeir, "Probiotics, prebiotics, and synbiotics," Advances in Biochemical Engineering/Biotechnology, vol. 111, pp. 1-66, 2008.

[16] H. J. Roy and B. Kalicki, "Probiotics," Pennington Nutrition, vol. 5, pp. 1-3, 2009.

[17] Y. K. Lee and S. Salminen, "The coming of age of probiotics," Trends in Food Science and Technology, vol. 6, no. 7, pp. 241-245, 1995.

[18] Y. Rivera-Espinoza and Y. Gallardo-Navarro, "Non-dairy probiotic products," Food Microbiology, vol. 27, no. 1, pp. 1-11, 2010.

[19] A. C. Brown and A. Valiere, "Probiotics and medical nutrition therapy," Nutrition in Clinical Care, vol. 7, no. 2, pp. 56-68, 2004.

[20] G. R. Lichtenstein, The Clinician's Guide to Inflammatory Bowel Disease, Slack, Thorofare, NJ, USA, 2003.

[21] L. V. McFarland and G. W. Elmer, "Biotherapeutic agents: past, present and future," Microecology and Therapy, vol. 23, pp. 4673, 1995.

[22] R. W. Jack, J. R. Tagg, and B. Ray, "Bacteriocins of gram-positive bacteria," Microbiological Reviews, vol. 59, no. 2, pp. 171-200, 1995.

[23] G. R. Gibson and M. B. Roberfroid, "Dietary modulation of the human colonic microbiota: introducing the concept of prebiotics," Journal of Nutrition, vol. 125, no. 6, pp. 1401-1412, 1995.

[24] M. B. Roberfroid, "Prebiotics and probiotics: are they functional foods?" American Journal of Clinical Nutrition, vol. 71, no. 6, pp. 1682S-1687S, 2000.

[25] P. C. Macgillivray, H. V. Finlay, and T. B. Binns, "Use of lactulose to create a preponderance of Lactobacilli in the intestine of bottle-fed infants," Scottish Medical Journal, vol. 4, no. 4, pp. 182-189, 1959.

[26] G. R. Gibson and R. Fuller, "Aspects of in vitro and in vivo research approaches directed toward identifying probiotics and prebiotics for human use," Journal of Nutrition, vol. 130, no. 2, pp. 391S-395S, 2000.

[27] L.-G. Ooi and M.-T. Liong, "Cholesterol-lowering effects of probiotics and prebiotics: a review of in vivo and in vitro findings," International Journal of Molecular Sciences, vol. 11, no. 6, pp. 2499-2522, 2010.

[28] J. H. Cummings, G. T. Macfarlane, and H. N. Englyst, "Prebiotic digestion and fermentation," American Journal of Clinical Nutrition, vol. 73, no. 2, pp. 415-420, 2001. 
[29] D. S. Newburg, "Innate immunity and human milk," Journal of Nutrition, vol. 135, no. 5, pp. 1308-1312, 2005.

[30] M. B. De Morais and C. M. A. Jacob, "The role of probiotics and prebiotics in pediatric practice," Jornal de Pediatria, vol. 82, no. 2, pp. S189-S197, 2006.

[31] C. J. Ziemer and G. R. Gibson, "An overview of probiotics, prebiotics and synbiotics in the functional food concept: perspectives and future strategies," International Dairy Journal, vol. 8, no. 56, pp. 473-479, 1998.

[32] T. Chikai, H. Nakao, and K. Uchida, "Deconjugation of bile acids by human intestinal bacteria implanted in germ-free rats," Lipids, vol. 22, no. 9, pp. 669-671, 1987.

[33] D. K. Walker and S. E. Gilliland, "Relationship among bile tolerance, bile salt deconjugation, and assimilation of cholesterol by Lactobacillus acidophilus," Journal of dairy science, vol. 76, no. 4, pp. 956-961, 1993.

[34] I. De Smet, L. van Hoorde, N. De Saeyer, M. Vande Woestyne, and W. Verstraete, "In vitro study of bile salt hydrolase (BSH) activity of BSH isogenic Lactobacillus plantarum 80 strains and estimation of cholesterol lowering through enhanced $\mathrm{BSH}$ activity," Microbial Ecology in Health and Disease, vol. 7, no. 6, pp. 315-329, 1994.

[35] O. Oner, B. Aslim, and S. B. Aydaş, "Mechanisms of cholesterollowering effects of lactobacilli and bifidobacteria strains as potential probiotics with their bsh gene analysis," Journal of Molecular Microbiology and Biotechnology, vol. 24, no. 1, pp. 1218, 2013.

[36] K. Tahri, J. P. Grill, and F. Schneider, "Bifidobacteria strain behavior toward cholesterol: coprecipitation with bile salts and assimilation," Current Microbiology, vol. 33, no. 3, pp. 187-193, 1996.

[37] M. L. Jones, H. Chen, W. Ouyang, T. Metz, and S. Prakash, "Microencapsulated genetically engineered Lactobacillus plantarum 80 (pCBH1) for bile acid deconjugation and its implication in lowering cholesterol," Journal of Biomedicine and Biotechnology, vol. 2004, no. 1, pp. 61-69, 2004.

[38] H.-J. Lim, S.-Y. Kim, and W.-K. Lee, "Isolation of cholesterollowering lactic acid bacteria from human intestine for probiotic use," Journal of Veterinary Science, vol. 5, no. 4, pp. 391-395, 2004.

[39] G. V. Mann and A. Spoerry, "Studies of a surfactant and cholesteremia in the Maasai," American Journal of Clinical Nutrition, vol. 27, no. 5, pp. 464-469, 1974.

[40] J. W. Anderson and S. E. Gilliland, "Effect of fermented milk (yogurt) containing Lactobacillus acidophilus L1 on serum cholesterol in hypercholesterolemic humans," Journal of the American College of Nutrition, vol. 18, no. 1, pp. 43-50, 1999.

[41] M. T. Liong and N. P. Shah, "Acid and bile tolerance and cholesterol removal ability of lactobacilli strains," Journal of Dairy Science, vol. 88, no. 1, pp. 55-66, 2005.

[42] J.Z. Xiao, S. Kondo, N. Takahashi et al., "Effects of milk products fermented by Bifidobacterium longum on blood lipids in rats and healthy adult male volunteers," Journal of Dairy Science, vol. 86, no. 7, pp. 2452-2461, 2003.

[43] B. Lavanya, S. Sowmiya, S. Balaji, and B. Muthuvelan, "Plasmid profiling and curing of Lactobacillus strains isolated from fermented milk for probiotic applications," Advance Journal of Food Science and Technology, vol. 3, no. 2, pp. 95-101, 2011.

[44] Y. Kim, J. Y. Whang, K. Y. Whang, S. Oh, and S. H. Kim, "Characterization of the cholesterol-reducing activity in a cellfree supernatant of Lactobacillus acidophilus ATCC 43121,"
Bioscience, Biotechnology and Biochemistry, vol. 72, no. 6, pp. 1483-1490, 2008.

[45] I. P. Kaur, K. Chopra, and A. Saini, "Probiotics: potential pharmaceutical applications," European Journal of Pharmaceutical Sciences, vol. 15, no. 1, pp. 1-9, 2002.

[46] R. G. Crittenden and M. J. Playne, "Production, properties and applications of food-grade oligosaccharides," Trends in Food Science and Technology, vol. 7, no. 11, pp. 353-361, 1996.

[47] T. S. Manning and G. R. Gibson, "Prebiotics," Best Practice and Research: Clinical Gastroenterology, vol. 18, no. 2, pp. 287-298, 2004.

[48] F. Brighenti, M. C. Casiraghi, E. Canzi, and A. Ferrari, "Effect of consumption of a ready-to-eat breakfast cereal containing inulin on the intestinal milieu and blood lipids in healthy male volunteers," European Journal of Clinical Nutrition, vol. 53, no. 9, pp. 726-733, 1999.

[49] M. L. Fernandez, S. Roy, and M. Vergara-Jimenez, "Resistant starch and cholestyramine have distinct effects on hepatic cholesterol metabolism in guinea pigs fed a hypercholesterolemic diet," Nutrition Research, vol. 20, no. 6, pp. 837-849, 2000.

[50] J. L. Causey, J. M. Feirtag, D. D. Gallaher, B. C. Tungland, and J. L. Slavin, "Effects of dietary inulin on serum lipids, blood glucose and the gastrointestinal environment in hypercholesterolemic men," Nutrition Research, vol. 20, no. 2, pp. 191-201, 2000.

[51] A. Mortensen, M. Poulsen, and H. Frandsen, "Effect of a longchained fructan Raftiline HP on blood lipids and spontaneous atherosclerosis in low density receptor knockout mice," Nutrition Research, vol. 22, no. 4, pp. 473-480, 2002.

[52] M.-L. Favier, C. Moundras, C. Demigne, and C. Remesy, "Fermentable carbohydrates exert a more potent cholesterollowering effect than cholestyramine," Biochimica et Biophysica Acta, vol. 1258, no. 2, pp. 115-121, 1995.

[53] M. T. Liong and N. P. Shah, "Effects of a Lactobacillus casei synbiotic on serum lipoprotein, intestinal microflora, and organic acids in rats," Journal of Dairy Science, vol. 89, no. 5, pp. 13901399, 2006.

[54] G. Schaafsma, W. J. A. Meuling, W. Van Dokkum, and C. Bouley, "Effects of a milk product, fermented by Lactobacillus acidophilus and with fructo-oligosaccharides added, on blood lipids in male volunteers," European Journal of Clinical Nutrition, vol. 52, no. 6, pp. 436-440, 1998. 

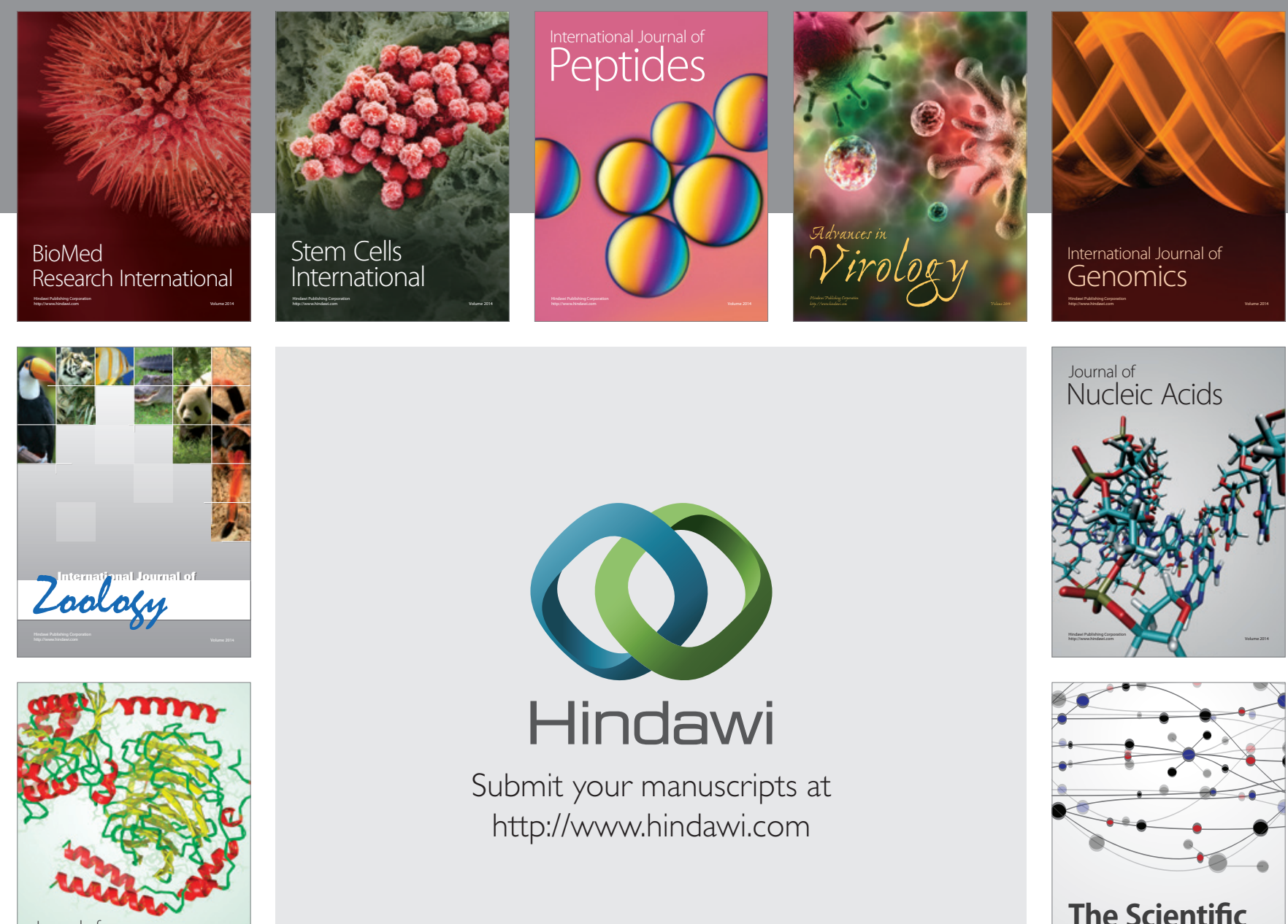

Submit your manuscripts at

http://www.hindawi.com

Journal of
Signal Transduction
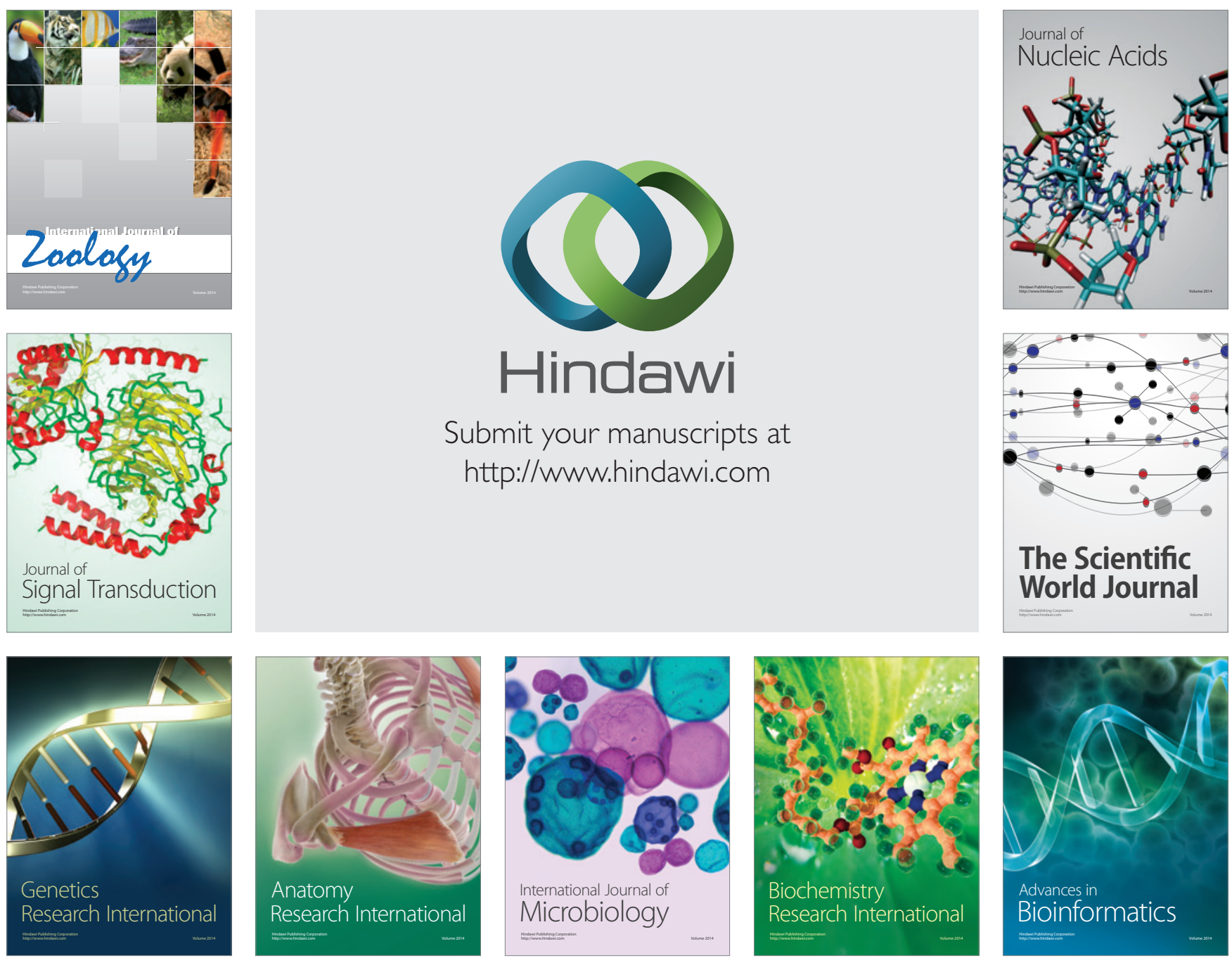

The Scientific World Journal
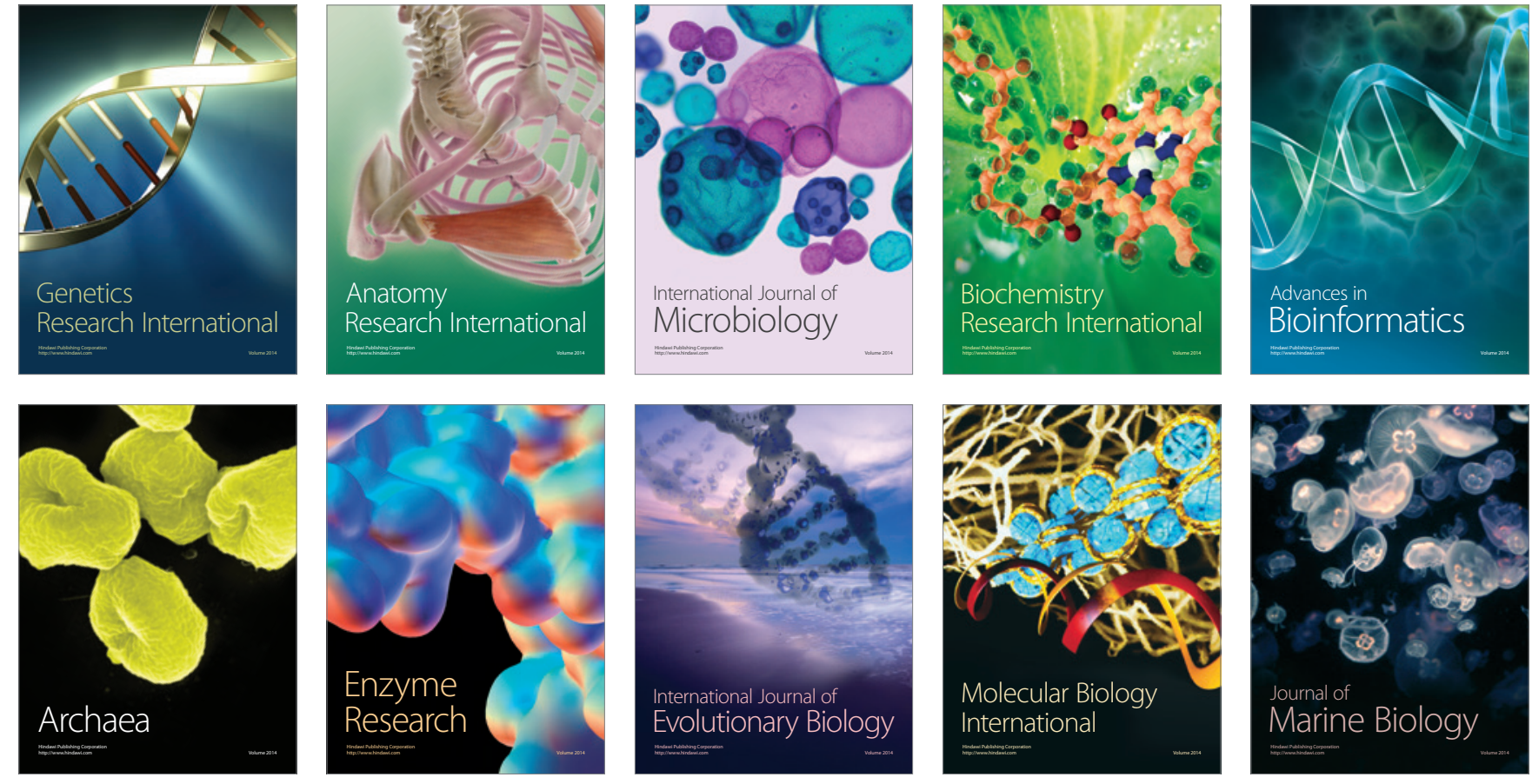